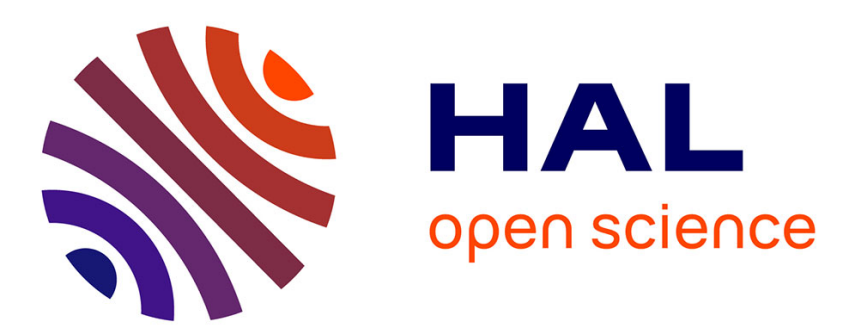

\title{
Novel role for the Lu/BCAM-spectrin interaction in actin cytoskeleton reorganization
}

Emmanuel Collec, Marie-Christine Lecomte, Wassim El-Nemer, Yves Colin, Caroline Le van Kim

\section{- To cite this version:}

Emmanuel Collec, Marie-Christine Lecomte, Wassim El-Nemer, Yves Colin, Caroline Le van Kim. Novel role for the Lu/BCAM-spectrin interaction in actin cytoskeleton reorganization. Biochemical Journal, 2011, 436 (3), pp.699-708. 10.1042/BJ20101717 . hal-00596275

\section{HAL Id: hal-00596275 https://hal.science/hal-00596275}

Submitted on 27 May 2011

HAL is a multi-disciplinary open access archive for the deposit and dissemination of scientific research documents, whether they are published or not. The documents may come from teaching and research institutions in France or abroad, or from public or private research centers.
L'archive ouverte pluridisciplinaire HAL, est destinée au dépôt et à la diffusion de documents scientifiques de niveau recherche, publiés ou non, émanant des établissements d'enseignement et de recherche français ou étrangers, des laboratoires publics ou privés. 


\title{
Novel role for the Lu/BCAM-spectrin interaction in actin cytoskeleton reorganization
}

\author{
Emmanuel Collec, Marie-Christine Lecomte, Wassim El Nemer, Yves Colin, Caroline Le Van Kim* \\ From Inserm, UMR-S 665, Paris, F-75015, France; Université Paris Diderot - Paris 7, Paris, F-75013, \\ France; Institut National de la Transfusion Sanguine, Paris, F-75015, France.
}

\begin{abstract}
*to whom correspondence should be addressed: Caroline Le Van Kim, INSERM, UMRS 665, INTS, 6 rue Alexandre Cabanel, 75015 Paris, France. Phone: international +33.1.44493046. FAX: international +33.1.43065019. E-mail: caroline.le-van-kim@inserm.fr
\end{abstract}

Short title: Lu/BCAM- $\alpha$ II spectrin interaction 


\section{Synopsis}

$\mathrm{Lu} / \mathrm{BCAM}$ is a laminin 511/521 receptor, expressed in erythroid and endothelial cells, and in epithelial tissues. The RK573-574 motif of Lu/BCAM cytoplasmic domain interacts with $\alpha$ I-spectrin, the main component of the membrane skeleton in red blood cells. We report that Lu/BCAM binds to the non-erythroid $\alpha$ II-spectrin via the RK573-574 motif. Alanine substitution of this motif abolished the Lu/BCAM-spectrin interaction, enhanced Lu/BCAM half-life at the MDCK cell surface and increased Lu/BCAM-mediated cell adhesion and spreading on laminin 511/521. We showed that the $\mathrm{Lu} / \mathrm{BCAM}$-spectrin interaction mediated actin reorganization during cell adhesion and spreading on laminin 511/521. This interaction was involved in a laminin 511/521 to actin signaling pathway leading to stress fibers formation. This skeleton rearrangement was associated with an activation of the small GTP binding protein RhoA, which depended on the integrity of the Lu/BCAM laminin 511/521 binding site. It also required the $\mathrm{Lu} / \mathrm{BCAM}-\alpha \mathrm{II}-$ spectrin interaction since its disruption decreased stress fibers formation and RhoA activation. We conclude that the Lu/BCAM-spectrin interaction is required for stress fibers formation during cell spreading on laminin 511/521 and that spectrin acts as a signal relay between laminin 511/521 and actin that is involved in actin dynamics.

Keywords : Lu/BCAM, adhesion molecule, laminin, MDCK, spectrin, cell adhesion, actin, RhoA

The abbreviations used are:

$\mathrm{Lu} \quad$ Lutheran

BCAM basal cell adhesion molecule

RBC Red Blood Cell

GST glutathione-S-transferase

$\alpha \mathrm{R} 4 \quad$ repeat 4 of $\alpha$-spectrin

MDCK Madin-Darby canine kidney

Ubc9 Ubiquitin enzyme conjugating 9 


\section{INTRODUCTION}

$\mathrm{Lu} / \mathrm{BCAM}$ glycoprotein (gp) is a member of the immunoglobulin superfamily (IgSF) that carries both the Lutheran ( $\mathrm{Lu}$ ) blood group antigens and the Basal Cell Adhesion Molecule (BCAM) tumoral antigen. It is represented by two isoforms, $\mathrm{Lu}$ and $\mathrm{Lu}(\mathrm{v} 13)$, that only differ by the length of their cytoplasmic domain (59 vs. 19 amino acids) [1]. The Lu gp specific cytoplasmic 40 amino acids comprise phosphorylation sites [2] and an SH3 binding motif, consistent with a receptor signaling function. $\mathrm{Lu} / \mathrm{BCAM}$ represents the unique receptor for laminin 511/521 (made of $\alpha 5 \beta 1 \gamma 1$ and $\alpha 5 \beta 2 \gamma 1$ chains, respectively) [3] in normal and sickle red blood cells (RBCs) [4-6]. In human blood cells, $\mathrm{Lu} / \mathrm{BCAM}$ is expressed only in erythrocytes. $\mathrm{Lu} / \mathrm{BCAM}$ is also present at the basal layer of epithelia, on the surface of a subset of muscle cells, and on blood vessel endothelium [7-9]. In these tissues, $\mathrm{Lu} / \mathrm{BCAM}$ is recognized as a coreceptor with integrins for laminin 511/521 [8]. Disruption of the $L U$ gene in mouse provided evidence that Lu/BCAM was involved in the maintenance of normal basement membrane organization in kidney and intestine [10].

In RBCs, Lu/BCAM interacts directly with spectrin through the juxtamembrane RK573-574 residues of its cytoplasmic tail [11-13]. Identified at the inner membrane of erythrocytes, spectrins are considered as the central components of a ubiquitous and complex spectrin-actin scaffold, called the spectrin-based skeleton [14]. This network, attached to diverse cellular membranes, is involved in diverse functions including the resilience and stability of membranes, the establishment of specialized membrane domains and in vesicle trafficking. Spectrins exist as elongated flexible hetero-tetramers of $200 \mathrm{~nm}$ made of two $\alpha$ and $\beta$ subunits that constitute the filaments of the network, the nodes of which are cross-linked by actin filaments. In mammals, two genes encode for $\alpha$-chains ( $\alpha$ I and $\alpha$ II) and five for $\beta$-chains. While $\alpha \mathrm{I}$-spectrin is the only isoform expressed in mature erythrocytes, $\alpha \mathrm{II}$-spectrin is the most common form in nucleated cells. Moreover, $\alpha \mathrm{I}$-spectrin is not expressed in epithelial cells. Each spectrin subunit is organized as an alignment of spectrin repeats, made of three $\alpha$-helices each; $\alpha$ spectrins contain 20 spectrin repeats. In RBCs, the Lu/BCAM binding site in $\alpha$ I-spectrin has been delimited to the single $\alpha 4$ repeat [15]. As Lu/BCAM represents a minor component of the RBCs membrane (from 1.500 to 4.000 copies/RBC), we have speculated that the $\mathrm{Lu} / \mathrm{BCAM}$-spectrin interaction might be critical for cell signaling rather than for maintenance of the membrane mechanical properties [12].

The adhesion properties of Lu/BCAM depend on its cytoplasmic domain phosphorylation, indicating an inside-out activating signal for its laminin 511/521 receptor function [2]. The physiologic stress mediator epinephrine, acting through the $\beta 2$-adrenergic receptor, increases Lu/BCAM-mediated adhesion of sickle RBCs to laminin 511/521 through a protein kinase A (PKA) dependent pathway [16]. Lu/BCAM phosphorylation by PKA occurs in sickle but not in normal RBCs, concomitantly with an enhanced cell adhesion to laminin 511/521 under physiological conditions [2]. In polycythemia vera patients, who present an increased risk of thrombosis, Lu/BCAM is constitutively phosphorylated and this feature is associated with an increased RBCs adhesion to endothelial laminin 511/521 [17].

In resealed $\mathrm{RBC}$ ghosts, disruption of the $\mathrm{Lu} / \mathrm{BCAM}$-spectrin interaction by a spectrin peptide encompassing the $\alpha 4$ repeat resulted in a weakened linkage of Lu/BCAM to the spectrin-based skeleton and induced cell adhesion to laminin 511/521 [15]. Increased adhesion of RBCs from Hereditary Spherocytosis (HS) patients with a marked deficiency in spectrin, demonstrated the biological relevance of this interaction: intact HS RBCs exhibited reinforced adhesion to laminin 511/521 under physiological conditions that resulted, at least in part, from an impaired interaction between Lu/BCAM and the membrane skeleton [18]. All these observations indicate that Lu/BCAM interaction with erythroid spectrin negatively regulates cell adhesion to laminin 511/521. 
In the present study, we showed that Lu/BCAM bound in vitro and ex vivo to non-erythroid $\alpha \mathrm{II}-$ spectrin in kidney epithelial cells. This interaction modulated spreading and adhesion of MDCK cells to laminin 511/521. Most importantly, we showed that the Lu/BCAM-spectrin interaction was involved in a laminin 511/521 to actin signaling pathway promoting actin skeleton reorganization.

\title{
EXPERIMENTAL
}

The Protease Inhibitor Cocktail, Micro Spin GST Purification Module and Protein-A-Sepharose were purchased from Amersham Biosciences. Br-cAMP was from Calbiochem (Darmstadt, Germany). Primers used in Polymerase Chain Reaction and mutagenesis experiments were from MWG biotech (Ebersberg, Germany). The in vitro transcription and translation TNT ${ }^{\circledR}$ T7 Quick kit for PCR-amplified DNA was obtained from Promega. Dako was from DakoCytomation. Phosphatase Inhibitor Cocktail (P.I.C) for serine/threonine phosphatase, purified human laminin 511/521 mixture, fibronectin and 30\% (W/V) BSA were supplied by Sigma. Lab-Tek ${ }^{\circledR}$ II Chamber Slide ${ }^{\mathrm{TM}}$ was from Nalge Nunc. SulfoNHS-LC-biotin and immunopure immobilized streptavidin beads were obtained from Pierce. GLISA $^{\text {TM }}$ RhoA, Rac and Cdc42 Activation Assay Biochem Kit ${ }^{\mathrm{TM}}$ (absorbance Based), cell-permeable Rho Inhibitor (exoenzyme C3 transferase, CT04) were from Cytoskeleton Inc (Denver, CO). ImageiTFX signal enhancer, Calcein-AM, bis-benzimidazole Hoechst 33342, AlexaFluor ${ }^{\circledR} 488$ Phalloidin, and NuPAGE $®$ Novex Bis-Tris Gels were purchased from Invitrogen. Cell culture media and reagents were from Gibco BRL. Except when otherwise mentioned, reagents were purchased from SigmaAldrich (Saint Louis, MO, USA). $12 \mathrm{~mm}$ diameter, $0.4 \mu \mathrm{M}$ pore Transwell polycarbonate filters were obtained from Costar. Millipore Electrical resistance apparatus was from Bedford. "Bio Imaging Analyser" was obtained from Fujifilm-Raytest. Evolution VF camera was from Mediacybergetics. 490 nm Multiskan RC was purchased from labsystems.

\begin{abstract}
Antibodies
Antibodies directed against Lu/BCAM; monoclonal antibody (MoAb) clone F241 and the rabbit polyclonal antibody (PoAb) 602 (collaboration with Dr D. Blanchard EFS, Nantes and INTS, Paris, France). The immunopurified PoAb directed against the $\alpha$ II-spectrin SH3 domain was produced in our labs [19]. Goat biotinylated anti-Lu/BCAM antibody (R\&D systems). Sheep anti-Human Ubc9 (A.G.Scientific Inc). AlexaFluor ${ }^{\circledR} 488$ conjugated anti-mouse, AlexaFluor ${ }^{\circledR} 568$ conjugated anti-rabbit antibodies (Molecular Probes, Invitrogen).
\end{abstract}

\section{Cell lines}

Human kidney carcinoma epithelial cells A498 (ATCC: HB44) were maintained in Minimal Essential Medium (MEM) Glutamax I supplemented with 10\% fetal bovine serum, 100 units $/ \mathrm{ml}$ antibiotic antimycotic, $1 \mathrm{mM}$ sodium pyruvate, $0.1 \mathrm{mM}$ Non Essential Amino Acids, Madin-Darby Canine Kidney cells (MDCK) (ATCC: CCL-34) were maintained in Dulbecco's Modified Eagle's Medium (DMEM) Glutamax I supplemented with 10\% fetal bovine serum, 100 units $/ \mathrm{ml}$ antibiotic antimycotic, $0.1 \mathrm{mM}$ Non-Essential amino acids. Both cell lines were grown in a humidified atmosphere at $37^{\circ} \mathrm{C}$ with $5 \% \mathrm{CO}_{2}$.

The full length wild-type cDNA sequence of Lu/BCAM (wt-Lu) and bearing the RK573-574AA (mt$\mathrm{Lu})(+1$ taken as the methionine of the initiation codon) were cloned in the pcDNA3 expression vector as described $[12,20]$. D343R mutation $(+1$ taken as the methionine of the initiation codon; the mutated residue is the same as residue 312 in reference [21] where +1 was taken as the first residue of the mature protein) was obtained by in vitro mutagenesis using sense primer, 5'AGAGTGGAGGATTACCGGGCGGCAGATGACGTG-3' and antisense primer, 5'CACGTCATCTGCCGCCCGGTAATCCTCCACTCT-3' . Stable MDCK cells expressing wt and 
mutant Lu/BCAM, were obtained and amplified as described [22]. To obtain clones showing similar Lu antigen membrane expression [specific antibody binding capacity (SABC) units], cell clones were selected by serial limit dilution [22]. The SABC for wt-Lu and for mt-Lu, were 456.337 and 401.887 , respectively.

\section{Protein extraction from MDCK cells}

After trypsin treatment, the pellet corresponding to $2.10^{6}$ MDCK cells was incubated for 1 hour at $4{ }^{\circ} \mathrm{C}$ in $400 \mu \mathrm{l}$ of lysis buffer $(20 \mathrm{mM} \mathrm{pH} 8$ Tris $\mathrm{HCl}, 150 \mathrm{mM} \mathrm{NaCl}, 5 \mathrm{mM}$ EDTA, 0.2\% BSA) supplemented with 0.010 to $0.030 \%$ Triton X-100, protease inhibitor cocktail). After centrifugation $\left(15,000 \mathrm{~g}, 15 \mathrm{~min}, 4^{\circ} \mathrm{C}\right)$, the soluble cell extract (S) was loaded on a 4-12\% NuPAGE $®$ Novex Bis-Tris Gels under reducing conditions. Proteins were analyzed by Western blot using Goat biotinylated anti$\mathrm{Lu} / \mathrm{BCAM}$ antibody $(0.1 \mu \mathrm{g} / \mathrm{ml})$ and Sheep anti-human $\mathrm{Ubc} 9(1: 3,000)$ as extraction control.

\section{Co-immunoprecipitation assay}

Cells $\left(10^{7}\right)$ were lysed for $30 \mathrm{~min}$ on ice in lysis buffer $(20 \mathrm{mM} \mathrm{pH} 8$ Tris $\mathrm{HCl}, 500 \mathrm{mM} \mathrm{NaCl}, 2 \mathrm{mM}$ $\mathrm{MgCl}_{2}, 1 \%$ Triton X-100 supplemented with protease inhibitor cocktail). Cell lysates were then sonicated and spin for $10 \mathrm{~min}$ at $11,000 \mathrm{~g}$.

$\mathrm{Lu} / \mathrm{BCAM}$ were immunoprecipitated by incubating overnight at $4^{\circ} \mathrm{C}$ the supernatants with either antiLu mouse MoAb F241 or an irrelevant antibody (Moab anti-IgG1) or only with protein-A-sepharose as negative control. The beads were spin at $11,000 \mathrm{~g}$ for $20 \mathrm{~min}$, and were washed five times with wash buffer $1(20 \mathrm{mM}$ pH 7.4 Tris $\mathrm{HCl}, 600 \mathrm{mM} \mathrm{NaCl}, 2 \mathrm{mM} \mathrm{MgCl}, 1 \%$ Triton X-100 supplemented with protease inhibitor cocktail) and twice in buffer $2(20 \mathrm{mM} \mathrm{pH} 7.4$ Tris $\mathrm{HCl})$ to remove traces of detergent. Immunoprecipitated proteins were first eluted with glycine/HCl buffer $\mathrm{pH} 3.2$ then equilibrated in Tris/HCl buffer $\mathrm{pH} 9$ for 5 min incubation. Samples were loaded on a $4-12 \% \mathrm{NuPAGE}^{\circledR}$ Novex Bis-Tris Gels under reducing conditions. Western blot analysis were performed using PoAb anti- $\alpha$ II-spectrin SH3 domain antibody $(1: 100,000)$ or Goat biotinylated anti-Lu/BCAM antibody $(0.1$ $\mu \mathrm{g} / \mathrm{ml})$.

\section{GST-pull down assays}

GST peptides were produced as previously described [12] and immobilized on Sepharose-4B glutathione beads micro spin columns. Briefly, PCR amplified cDNA fragments encoding the Cterminal ends of Lu/BCAM (residues 569 to 628), were fused with the GST protein in the pGEX-5X-3 plasmid. mt-Lu RK573-574AA was obtained by in vitro mutagenesis as described [12]. Spectrin repeat units corresponding to $\alpha$ IR3 amino acids (A253 to G384), $\alpha$ IIR3 (Q255 to L382), $\alpha$ IR4 (S361 to E486), $\alpha$ IIR4 (E361 to E486), $\alpha$ IR3-5 (A253 to L594), $\alpha$ IIR3-5 (Q255 to L594), $\alpha$ IR5 (D466 to L594), $\alpha$ IIR5 (L467 to L594) were obtained as a $\left[{ }^{35} \mathrm{~S}\right]$ Met-labeled protein with the in vitro transcription and translation $\mathrm{TNT}^{\circledR} \mathrm{T} 7$ Quick kit for PCR-amplified DNA.

The products $(50 \mu \mathrm{l})$ were incubated overnight at $4{ }^{\circ} \mathrm{C}$ with GST-wt-Lu and GST-mt-Lu constructs $(100$ $\mu \mathrm{g}$ ) immobilized on Sepharose 4B glutathione beads equilibrated in phosphate buffer saline (PBS) and antiproteases. After five washes with PBS $0.05 \%$ Tween 20 , the bound proteins were solubilized in Laemmli sample buffer [23], loaded on a 4-12\% NuPAGE ${ }^{\circledR}$ Novex Bis-Tris Gels, visualized and quantified by KODAK ID Image analysis software.

\section{Confocal fluorescence microscopy and immunofluorescence of transfected cells}

The transepithelial resistance was measured daily on stably transfected MDCK cells grown onto polycarbonate filters $\left(5.10^{5}\right.$ cells/filter). At day 7 , polarized cells were fixed $20 \mathrm{~min}$ with $4 \%$ paraformaldehyde, treated with $50 \mathrm{mM} \mathrm{NH}_{4} \mathrm{Cl}$ in PBS, permeabilized 10 min with $0.5 \%$ Triton (PBS) and incubated with F241 anti-Lu MoAb (1:10) and the polyclonal anti-aII-spectrin SH3 domain 
antibody (1:500) in Dako for $1 \mathrm{~h}$ at room temperature. Filters were washed with PBS- $0.5 \%$ BSA and incubated with AlexaFluor ${ }^{\circledR} 488$ and 568 conjugated anti-mouse and anti-rabbit antibodies (1:200) for $1 \mathrm{hr}$ at RT, washed with PBS- $0.5 \%$ BSA. Samples were examined by confocal microscopy using a NIKON EC-1 system equipped with $60 \times$ NA 1.4 and $100 \times 1.30$ objectives.

Lab-Tek ${ }^{\circledR}$ II Chamber Slide ${ }^{\mathrm{TM}}$ were coated with $2 \mu \mathrm{g} / \mathrm{cm}^{2}$ of either laminin $511 / 521$ or fibronectin overnight at $4^{\circ} \mathrm{C}$ (in $400 \mu \mathrm{l}$ ). Wells were then washed twice with PBS and were subsequently coated with $1 \% \mathrm{BSA}$ at $37^{\circ} \mathrm{C}$ for 1 hour before two additional washes. $10^{4}$ mocktransfected MDCK cells or transfected cells expressing wt-Lu, mt-Lu, D343R Lu mutant or Lu(v13) were added to the wells (in $400 \mu \mathrm{l}$ ). Cells were incubated in in serum-free medium for $90 \mathrm{~min}$ at $37^{\circ} \mathrm{C}$ in presence or absence of $1 \mu \mathrm{g} / \mathrm{ml}$ per well of the cell-penetrating form of the Clostridium botulinum $\mathrm{C} 3$ toxin, an ADP ribosyltransferase that selectively ribosylates Rho proteins, rendering them inactive After this incubation time, cells were fixed 20 min with $4 \%$ paraformaldehyde, treated with $50 \mathrm{mM}$ $\mathrm{NH}_{4} \mathrm{Cl}$ in PBS, permeabilized 10 min with $0.5 \%$ Triton (PBS), saturated 30 min in Image-iTFX signal enhancer solution. Cells were washed with PBS- $0.5 \%$ BSA and incubated with Phalloidin AlexaFluor ${ }^{\circledR}$ 488 (1:50) for $1 \mathrm{~h}$ at RT. Samples were examined by confocal microscopy.

\section{Cell surface biotinylation assay}

Polarized MDCK monolayers expressing either wt-Lu or mt-Lu were cultured on filters as described above. Newly synthesized proteins were labeled by adding $150 \mu \mathrm{Ci}\left[{ }^{35} \mathrm{~S}\right]$ methionine $/\left[{ }^{35} \mathrm{~S}\right]$ cysteine in the cell culture medium for $20 \mathrm{~min}$ incubation at $37^{\circ} \mathrm{C}$. After washing with complete medium, cells were incubated in non-radioactive medium for $60,90,120,150$ and $180 \mathrm{~min}$ at $37^{\circ} \mathrm{C}$. After each incubation time, cells were washed twice with cold PBS and incubated at the basolateral side with 0.5 $\mathrm{mg} / \mathrm{ml}$ Sulfo-NHS-LC-biotin. After immunoprecipitation of total Lu/BCAM, half of the eluted proteins were diluted with Laemmli 3X buffer (total Lu/BCAM) and the other half was incubated in $500 \mu$ of lysis buffer for $3 \mathrm{~h}$ with immunopure immobilized streptavidin beads to isolate membrane Lu/BCAM. Beads were washed three times with lysis buffer and Lu/BCAM was eluted in $20 \mu \mathrm{l}$ of Laemmli buffer for $5 \mathrm{~min}$ at $100^{\circ} \mathrm{C}$. Eluates from both steps (total and membrane Lu/BCAM) were analyzed by SDSPAGE on $8 \%$ polyacrylamide gel under reducing conditions followed by Western blot probed with rabbit polyclonal anti-Lu antibody 602 (1:5000). Samples of biotinylated Lu proteins were analyzed using a "Bio Imaging Analyser" to quantify the newly delivered membrane proteins as a function of time.

\section{Cell-spreading assay}

The 12 -wells plates were coated with either $2 \mu \mathrm{g} / \mathrm{cm} 2$ of laminin $511 / 521$ or $1 \%$ BSA overnight at $4^{\circ} \mathrm{C}$. Wells were washed twice with PBS and were subsequently coated with $1 \% \mathrm{BSA}$ at $37^{\circ} \mathrm{C}$ for $1 \mathrm{~h}$ before two additional washes. MDCK cells were washed twice and added to the wells $\left(10^{5}\right.$ per wells $)$ in serum-free medium. After different incubations time $(30,60$ and $90 \mathrm{~min})$ at $37^{\circ} \mathrm{C}$, spread and round cells were quantified in four representative areas by microscopy (Leitz, x100) using a computerized image analysis system (Biocom VisioL@b 2000). The counted cells were then averaged and presented as mean percentage of spread cells. A $p$ value greater than 0.05 was considered not significantly different.

\section{Cell matrix adhesion assay}

$2.10^{6}$ mock-transfected MDCK cells or transfected wt-Lu or mt-Lu cells were labeled with $5 \mu \mathrm{M}$ calcein-AM when $2.10^{6}$ MDCK -mt-Lu control cells were labeled with $1 \mu \mathrm{g} / \mathrm{ml} \mathrm{Hoechst} \mathrm{33342,30} \mathrm{min}$ at $37^{\circ} \mathrm{C} / 5 \% \mathrm{CO}_{2}$, then cells were washed twice with prewarmed serum-free medium. MDCK, wt-Lu or mt-Lu cells were then mixed with control cells as internal standard in a $1 / 1$ ratio. $1 \mathrm{ml}$ of the mixed cells was then put in laminin 511/521 pre-coated 12 well plates. After 90 min incubation at $37^{\circ} \mathrm{C} / 5 \%$ 
$\mathrm{CO}_{2}$, cells were washed twice with prewarmed serum-free medium to remove unattached cells and visualized by fluorescence using Evolution VF camera. Ten images were acquired for each sample, and adherent cells were count using Image-Pro ${ }^{\circledR}$ Plus software. Results are expressed as the mean percentage of adherent transfected cells versus control adherent cells.

\section{Phosphorylation assays in transfected cells}

MDCK-wt-Lu and mt-Lu $\left(5.10^{6}\right)$ growth in in 6-wells plates were washed three times in DMEM without phosphate and incubated in the same medium for $2 \mathrm{~h}$ at $37^{\circ} \mathrm{C}$. Cells were then incubated with $300 \mu \mathrm{Ci}$ of orthophosphate ${ }^{32} \mathrm{P}(25 \mathrm{mM})$ for $90 \mathrm{~min}$ at $37^{\circ} \mathrm{C}$ and one well with wt-Lu or mt-Lu cells was supplemented with 1X of P.I.C $(90 \mathrm{~min})$ or $1 \mathrm{mM}$ br-cAMP $(30 \mathrm{~min})$. Cells were washed twice with ice cold PBS and incubated in lysis buffer $(20 \mathrm{mM} \mathrm{pH} 8$ Tris $\mathrm{HCl}, 150 \mathrm{mM} \mathrm{NaCl}, 5 \mathrm{mM}$ EDTA, $1 \%$ Triton X-100, $0.2 \%$ BSA, supplemented with protease inhibitor cocktail and $1 \mathrm{X}$ PIC) for $1 \mathrm{~h}$ at $4^{\circ} \mathrm{C}$. Immunoprecipitation of Lu/BCAM was describing above (Co-immunoprecipitation assay). The beads were washed five times in lysis buffer. Immunoprecipitated proteins were first eluted 5 min at $100^{\circ} \mathrm{C}$ with $3 \mathrm{X}$ laemmli supplemented with $5 \%$ beta-mercapto-ethanol and then loaded on a $4-12 \%$ NuPAGE ${ }^{\circledR}$ Novex Bis-Tris Gels under reducing conditions. Analyzed was performed by Western blot using Goat biotinylated anti-Lu/BCAM antibody $(0.1 \mu \mathrm{g} / \mathrm{ml})$ or using the "Bio Imaging Analyser".

\section{Rho family proteins activation and inhibition assay}

The 6-wells plates were coated with laminin $511 / 521$ or fibronectin as described before. $25.10^{4}$ mocktransfected MDCK cells and wt-Lu or mt-Lu cells were added to the wells for $90 \mathrm{~min}$. Active Rac1, 2, 3 and RhoA were measured using the G-LISA ${ }^{\mathrm{TM}}$ Rac or RhoA or Cdc42 Activation Assay Biochem $\mathrm{Kit}^{\mathrm{TM}}$ according to the manufacturer's instructions. GTP Rac, RhoA and Cdc42 were used as positive control. The absorbance signals were detected at $490 \mathrm{~nm}$.

\section{Statistical analysis}

Results are expressed as mean. Data set were analyzed by the Mann-Whitney non parametric test to determine statistical significance between mt-Lu and wt-Lu. Statistical significance is defined as $\mathrm{p}<0.05$. 


\section{RESULTS}

\section{Lu/BCAM interacts with $\alpha$ II-spectrin in non-erythroid cells via its RK573-574 residues}

We investigated the potential interaction of Lu /BCAM with the $\alpha$ II-spectrin isoform expressed in nonerythroid cells. Immunoprecipitation (IP) assays were performed using two cell lines expressing endogenous Lu/BCAM: the human kidney epithelial cells A498 and the human microvascular endothelial cells HMEC-1. After Lu/BCAM IP, Western blotting (WB) analysis revealed the presence of $\alpha$ II-spectrin indicating that it was co-immunoprecipitated with $\mathrm{Lu} / \mathrm{BCAM}$ from A498 cells (Fig. 1A, left panel) and HMEC-1 cells (data not shown), and suggesting an interaction between these two proteins. Neither spectrin $(270 \mathrm{kDa})$ nor $\mathrm{Lu} / \mathrm{BCAM}(90 \mathrm{kDa})$ were detected when an irrelevant antibody (IgG1) or Protein A-Sepharose (PA) alone were used for IP. The RK573-574 residues of the cytoplasmic tail of $\mathrm{Lu} / \mathrm{BCAM}$ are required for binding to $\alpha \mathrm{I}$-spectrin in RBCs [12]. The involvement of these residues in the interaction with $\alpha$ II-spectrin was also investigated by IP using transfected MDCK cells expressing either wild-type Lu/BCAM (wt-Lu) or the RK573-574AA Lu/BCAM mutant (mt-Lu). As expected, $\alpha$ II-spectrin was co-immunoprecipitated with wt-Lu (Fig. 1A, right panel). Faint quantities of $\alpha$ II-spectrin, similar to those obtained with the IgG1 negative control, were detected from cells expressing mt-Lu (Fig. 1A, right panel), indicating that the RK573-574AA mutation abolished the $\mathrm{Lu} / \mathrm{BCAM}-\alpha$ II-spectrin interaction. These results indicated that endogenous and recombinant $\mathrm{Lu} / \mathrm{BCAM}$ interacted with $\alpha$ II-spectrin in both epithelial and endothelial cells; this interaction involved the Lu /BCAM cytoplasmic RK573-574 motif.

\section{Lu/BCAM binds to $\alpha 4$ repeat of $\alpha$ II-spectrin}

The Lu/BCAM cytoplasmic domain binds to $\alpha$ I-spectrin $\alpha 4$ repeat $(\alpha 4 \mathrm{R})$ in RBCs [15]. Sequence analyses revealed that the $\alpha$ II-spectrin $\alpha 4 \mathrm{R}$ (residues E361 to E486) shares $57 \%$ of identity with its $\alpha \mathrm{I}$ spectrin corresponding repeat. We tested the involvement of the $\alpha$ II-spectrin $\alpha 4 \mathrm{R}$ in the interaction with $\mathrm{Lu} / \mathrm{BCAM}$ using GST pull down assays. $\alpha 3 \mathrm{R}, \alpha 4 \mathrm{R}, \alpha 5 \mathrm{R}$ and $\alpha 3->5 \mathrm{R}$ were produced as $\left[{ }^{35} \mathrm{~S}\right]$ Met-labeled peptides by in vitro transcription and translation (TNT products) (Fig. 1B), and their binding activity to the cytoplasmic domain of Lu/BCAM, produced as a GST-fusion protein, was analyzed. As shown in Fig. 1B, the spectrin peptides encompassing either the $\alpha 3->5 R$ or only the $\alpha 4 R$ were pulled down with the wt-Lu cytoplasmic tail (GST-wt-Lu), giving a signal 3- to 5-fold higher than those obtained with either GST alone or the mt-Lu cytoplasmic domain (GST-mt-Lu). In contrast, the pull-down signals obtained with the $\alpha 3 \mathrm{R}$ and $\alpha 5 \mathrm{R}$ were similar for GST, GST-wt-Lu and GST-mt-Lu. These results indicated that $\alpha$ II-spectrin $\alpha 4 \mathrm{R}$ was involved in the interaction with the Lu/BCAM RK573-574 motif.

\section{Disruption of the Lu/BCAM-spectrin interaction increases Lu/BCAM extractability in epithelial cells}

To verify the involvement of the spectrin- Lu/BCAM interaction as a link between $\mathrm{Lu} / \mathrm{BCAM}$ and the membrane cytoskeleton, we examined the detergent solubility of recombinant wt-Lu and mt-Lu in epithelial MDCK cells. Cells were treated with increasing concentrations of Triton X-100 (0.01 to $0.1 \%$ ) and the amount of solubilized Lu/BCAM was analyzed by WB using the Ubiquitin-conjugating enzyme 9 (Ubc9) (20 kDa) as a cytoplasmic marker and loading control. As shown in Fig. 1C, wt-Lu was not detected in the soluble fraction below $0.025 \%$ of Triton X-100. Conversely, mt-Lu was extracted starting from $0.01 \%$ of Triton X-100 indicating that disruption of the Lu/BCAM-spectrin interaction increases the cytoskeleton-unbound Lu/BCAM fraction in non-erythroid cells. 


\section{Interaction with spectrin is not involved in the membrane targeting of Lu/BCAM}

The basolateral expression of Lu/BCAM in polarized epithelial cells depends on the integrity of a dileucine motif at position 608-609 of the cytoplasmic domain [24]. To determine the potential role of $\alpha$ II-spectrin in Lu/BCAM membrane targeting, confluent monolayers of MDCK clones expressing similar amounts of either wt-Lu (400,000 molecules/cell ) or mt-Lu (450,000 molecules/cell) were grown on filters, then labeled with both monoclonal anti-Lu/BCAM and polyclonal anti- $\alpha$ II-spectrin antibodies. Confocal microscopy analysis showed that both cell types exhibited a polarized phenotype and form tight junctions at confluence, as indicated by daily transepithelial resistance measurements (900 ohms/well after 7 days of culture). As shown in Fig. S1, spectrin (red) and wt-Lu (green) were expressed at the cell membrane and displayed a lateral expression, as expected. The merge panels (yellow) indicated that wt-Lu and spectrin were in the same lateral membrane compartment. The same pictures were obtained with MDCK cells expressing $\mathrm{mt}-\mathrm{Lu}$, indicating that disruption of the $\mathrm{Lu} / \mathrm{BCAM}$-spectrin interaction did not modify the Lu/BCAM membrane expression pattern. Therefore this interaction is not required for the correct lateral targeting of Lu/BCAM in polarized epithelial cells.

\section{Interaction with $\alpha$ II-spectrin plays a role in the stability of $\mathrm{Lu} / \mathrm{BCAM}$ at the epithelial cell membrane}

As the $\mathrm{Lu} / \mathrm{BCAM}$-spectrin interaction was not involved in the cell surface localization of $\mathrm{Lu} / \mathrm{BCAM}$, we investigated the putative role of this interaction in Lu/BCAM membrane delivery and turn-over using pulse-chase experiments combined with surface protein biotinylation.

As the newly-delivered $\mathrm{Lu} / \mathrm{BCAM}$ at the membrane has been reported to reach a peak between 60 and 90 min of chase [24], the chase experiment on polarized MDCK cells was started at 60 min after the radiolabeling step and followed up to $180 \mathrm{~min}$. Total cell surface proteins were labeled with biotin before cell lysis and IP. Total Lu/BCAM was immunoprecipitated and the biotinylated fraction, corresponding to $\mathrm{Lu} / \mathrm{BCAM}$ expressed at the cell membrane, was purified by streptavidin-agarose beads. The amounts of radiolabeled Lu/BCAM presents on the membrane after 60, 90, 120, 150 and 180 min were determined by SDS-PAGE of biotinylated proteins followed by autoradiography. Newlysynthesized wt-Lu and mt-Lu were correctly addressed to the lateral membrane as both were present at the cell surface after $60 \mathrm{~min}$ of chase (Fig. 2A). This result confirmed that the interaction with spectrin was not involved in Lu/BCAM membrane targeting. However, the turn-over of mt-Lu and wt-Lu were significantly different as shown by the extended mt-Lu half-life at the membrane. The newly delivered amounts of mt-Lu at 60 min remained unchanged up to 180 min while wt-Lu decreased soon after 60 min. This difference in kinetics was not due to protein degradation as WB showed that equivalent amounts of each protein were immunoprecipitated for all chase times (Fig. 2B).

To quantify the turn-over of both proteins, the intensity of all bands was determined and the ratio "radiolabeled /biotinylated" was calculated. As shown in Fig. 2C, radiolabeled wt-Lu decreased at the membrane over time with almost half of the proteins being internalized after $90 \mathrm{~min}$ as compared to $60 \mathrm{~min}$. Conversely, mt-Lu showed an enhanced stable membrane expression as newly delivered $\mathrm{mt}-\mathrm{Lu}$ did not undergo significant internalization up to $180 \mathrm{~min}$ of chase, indicating that the lack of interaction with spectrin decreases the membrane turn-over of Lu/BCAM in polarized MDCK cells.

\section{Interaction of $\mathrm{Lu} / \mathrm{BCAM}$ with spectrin modulates spreading and adhesion of epithelial cells to laminin 511/521}

Alteration of the spectrin-based skeleton as well as disruption of the Lu/BCAM-spectrin interaction resulted in an enhanced Lu/BCAM-mediated adhesion of RBCs and K562 cells to laminin 511/521 $[15,18]$. To investigate whether the interaction with spectrin could similarly modulate Lu/BCAMmediated adhesion of epithelial cells, we analyzed the spreading and adhesion to laminin 511/521 of MDCK cells expressing either wt-Lu or mt-Lu as described under "Experimental" (Fig. 3A). 
We first compared the ability of MDCK cells to spread on laminin 511/521 and BSA, used as negative control. Ninety minutes after plating, only $12 \%$ and $14 \%$ of mock-transfected MDCK cells could spread on BSA and laminin 511/521, respectively (Fig. 3B). MDCK cells expressing either wt$\mathrm{Lu}$ or mt-Lu presented a similar behavior on BSA but exhibited $38 \%$ and $60 \%$ of spread cells on laminin 511/521 at $90 \mathrm{~min}$, respectively (Fig. 3B). Cell spreading on laminin 511/521 was higher for $\mathrm{mt}-\mathrm{Lu}$ than for wt-Lu expressing cells and was observed as soon as $30 \mathrm{~min}$ after plating (29\% vs $14 \%)$.

Cell adhesion to laminin 511/521 was also investigated. As expected, Lu/BCAM expression increased cell adhesion to laminin 511/521 as evaluated by the percentage of adherent cells: $65 \%$ for wt-Lu vs 20\% for mock-transfected MDCK cells (Fig. 3C). Cell adhesion to laminin 511/521 was particularly reinforced for mt-Lu expressing cells with $95 \%$ of adherent cells. These results indicated that disruption of the Lu/BCAM-spectrin interaction significantly increased Lu/BCAM-mediated epithelial cell adhesion to laminin 511/521.

\section{The reinforced adhesion of mt-Lu expressing MDCK cells is not related to the Lu/BCAM phosphorylation status}

The increased adhesion of pathological red cells to laminin 511/521 is associated with PKA-mediated $\mathrm{Lu} / \mathrm{BCAM}$ phosphorylation $[2,17]$. As disruption of the Lu/BCAM-spectrin interaction reinforced the MDCK cell adhesion to laminin 511/521, we investigated whether this feature was related to a PKAstimulated Lu/BCAM phosphorylation. Phosphorylation assays were performed using MDCK cells expressing either wt-Lu or mt-Lu. Lu/BCAM was immunoprecipitated from ${ }^{32} \mathrm{P}$ radiolabeled cells in the presence of a serine/threonine phosphatases inhibitor cocktail (PIC), or of br-cAMP, a stable membrane permeable cAMP analog that activates PKA.

In the absence of activators, and 90 min after cell plating on laminin 511/521, both wt-Lu and mtLu presented a similar basal phosphorylation level, as shown by autoradiography and WB (Fig. 4, compare lanes 1 and 4). The amount of immunoprecipitated Lu/BCAM was estimated by WB and $\mathrm{Lu} / \mathrm{BCAM}$ phosphorylation was normalized by calculating the ratio of the phosphorylation signal and the WB intensity of each band. The phosphorylation level of both proteins was similarly induced in the presence of PIC and br-cAMP (Fig. 4), indicating that disruption of the Lu/BCAM-spectrin interaction did not alter the Lu/BCAM phosphorylation status.

\section{Lu/BCAM-spectrin interaction is required for stress fibers formation on laminin 511/521}

As cell adhesion and motility require actin rearrangements, we tested whether the Lu /BCAM-spectrin interaction could induce specific actin reorganization during MDCK cell adhesion and spreading. Low density plated cells were stained with phalloidin to label F-actin, $90 \mathrm{~min}$ after seeding on either laminin 511/521 (Fig. 5a-e) or fibronectin (Fig. 5f-j). Analyses were performed by confocal microscopy focusing on the cell basal membrane. In mock transfected cells, actin was detected as peripheral spikelike protrusions and cortical ring as well as cytoplasmic punctuated forms on both laminin 511/521 and fibronectin substrates (Fig. 5a,f). The same actin expression pattern was observed in all wt-Lu expressing cells plated on fibronectin (Fig. $5 \mathrm{~g}$ ). When these cells were plated on laminin 511/521, they exhibited a better spreading with extended lamellipodia. An increase in actin stress fibers was observed in $46 \%$ of $\mathrm{Lu} / \mathrm{BCAM}$ expressing cells (Fig. 5b). To determine the putative involvement of the Lu/BCAM-laminin 511/521 interaction in the stress fibers formation, MDCK cells expressing the D343R Lu/BCAM mutant, which is unable to bind to laminin 511/521 (the mutated residue is the same as residue 312 in reference [21]), were analyzed. These cells did not form stress fibers neither on laminin 511/521 nor on fibronectin (Fig. 5c,h). Absence of stress fibers was also observed for MDCK cells expressing mt-Lu, plated on laminin 511/521 or fibronectin (Fig. 5d,i). These results indicated that the stress fibers formation in MDCK cells plated on laminin 511/521 was induced by the Lu/BCAMlaminin 511/521 interaction and that the Lu/BCAM-spectrin interaction was involved in a laminin 
$511 / 521$ to actin signaling pathway leading to actin reorganization.

To determine the putative role of the $40 \mathrm{C}$-terminal amino acids of $\mathrm{Lu}$ gp in regulating stress fibers formation, the same experiment was performed using MDCK cells expressing the short isoform $\mathrm{Lu}$ (v13). This isoform is truncated for the $40 \mathrm{C}$-terminal amino acids comprising the proline-rich SH3binding domain, the dileucine motif, and the phosphorylation sites. Similarly to wt-Lu expressing cells, 64\% of cells expressing $\mathrm{Lu}(\mathrm{v} 13)$ were able to form stress fibers when plated on laminin 511/521 (Fig. 5e), indicating that $\mathrm{Lu} / \mathrm{BCAM}$-mediated actin reorganization was independent of its proline-rich SH3binding domain and of potential signaling events that could be mediated by its cytoplasmic tail.

\section{Laminin 511/521 activates a RhoA-dependent signaling pathway via the Lu/BCAM-spectrin interaction}

Rho GTPases are important regulators of the actin cytoskeleton and are involved in cell shape and motility. The activation of the small GTP-binding protein RhoA plays a role in stress fibers formation whereas Rac and Cdc42 are responsible for the actin polymerization in lamellipodia [25-27]. We compared RhoA, Rac and Cdc42 activities in mock-transfected MDCK cells and in cells expressing either wt-Lu or mt-Lu. Activities were evaluated from equal amounts of lysates obtained from cells plated for $90 \mathrm{~min}$ on either laminin 511/521 or fibronectin (Fig. 6). No changes could be observed in Rac and Cdc42 activity for all conditions (Fig. 6B,C). In contrast, cells expressing wt-Lu and plated on laminin 511/521 exhibited a significant increase of RhoA activity as compared to mock and mt-Lu cells (Fig. 6A). These data suggested the involvement of RhoA activation in the actin reorganization associated with the $\mathrm{Lu} / \mathrm{BCAM}$-spectrin interaction.

To further investigate the involvement of the RhoA pathway, we used the exoenzyme C3 transferase as a RhoA inhibitor. Pretreatment with the $\mathrm{C} 3$ transferase for 2 hours is sufficient to inhibit the stress fibers formation in wt-Lu and $\mathrm{Lu}(\mathrm{v} 13)$ MDCK cells plated on laminin 511/521 indicating that RhoA is necessary for the specific Lu/BCAM induced actin reorganization (Fig.7).

\section{DISCUSSION}

\section{Lu/BCAM interacts with spectrin in non-erythroid cells.}

This study identified the $\alpha$ II-spectrin isoform as a direct cytoplasmic partner of Lu/BCAM in vitro and ex vivo in different cellular contexts. The co-immunoprecipitation of endogenous spectrin with Lu/BCAM from kidney epithelial A498 cells gave the physiological relevance of the GST pull-down interactions.

Positively charged juxta-membrane amino acids in adhesion molecules, such as CD44 and ICAM-2, were shown to interact with cytoskeletal protein 4.1 and ERM proteins (ezrin, radixin, moesin) [28]. As in RBCs, Lu/BCAM RK573-574 motif interacted directly with $\alpha$ II-spectrin $\alpha 4 \mathrm{R}$ and it could be assumed that this interaction might occur in all cell types where these two proteins are expressed. In humans, $\alpha \mathrm{I}$ and $\alpha$ II-spectrins share $55 \%$ of identity in the amino acid sequence. $\alpha$ spectrins are composed of 20 repeats and $\alpha$ II-spectrin $\alpha 4 \mathrm{R}$ exhibits $57 \%$ of identity with its corresponding erythroid al-spectrin repeat. Moreover, Lu/BCAM RK573-574 motif and surrounding sequences are conserved in mammals.

\section{Effects of Lu/BCAM-spectrin interaction on Lu/BCAM membrane localization and stability}

Lu/BCAM is endogenously expressed in epithelial kidney A498 cells at 70,000 copies /cell [22]. Its lateral expression in polarized epithelial cells depends on the dileucine motif of its cytoplasmic domain [4].

Moreover, recruitment of $\mathrm{Lu} / \mathrm{BCAM}$ at the lateral surface in epithelial cells, adjacent to laminin $\alpha 5$-containing extracellular matrix, suggests a role for laminin 511/521 in its membrane localization 
[8]. Indeed, Lu/BCAM expression was dramatically reduced in various tissues of mouse embryos lacking laminin $\alpha 5$ chain, while it was significantly increased in the heart of transgenic mice overexpressing this chain $[29,30]$.

Our results pointed out the predominance of the dileucine motif for Lu/BCAM lateral targeting. Our immunostaining experiments indicated that interaction with spectrin was not required for the proper targeting of Lu/BCAM in polarized epithelial MDCK cells.

In conclusion, the RK motif does not appear to be involved in Lu/BCAM membrane targeting, but this interaction could play a role in $\mathrm{Lu} / \mathrm{BCAM}$ membrane turnover. In the pulse-chase experiments, we observed that Lu RK573-574AA mutant had an extended half-life at the cell surface. Since $\alpha$ IIspectrin interacts with syntaxin family proteins, which play a key role in the vesicle fusion during exocytosis and endocytosis [31], our results suggest that spectrin might be involved in Lu/BCAM turnover through the endocytic pathway.

\section{Role of the Lu/BCAM-spectrin interaction during cell spreading and adhesion.}

It was hypothesized that the Lu/BCAM-spectrin interaction might be critical for signaling and laminin $511 / 521$ receptor function rather than in the maintenance of the RBC shape. Lu/BCAM is involved in the abnormal adhesion of red cells to laminin 511/521 and endothelium in pathological situations [2, 5, $16,17]$. We and others have demonstrated that the interaction of $\mathrm{Lu} / \mathrm{BCAM}$ with erythroid spectrin negatively regulated its adhesive receptor function in normal and spectrin-deficient HS RBCs [15, 18]. In non-erythroid adherent cells, partial $\alpha$ II-spectrin depletion was associated with loss of cell spreading, defective adhesion and decrease and irregularity of focal adhesion points [32].

Our results showed that $\mathrm{Lu} / \mathrm{BCAM}$ plays a critical role during epithelial cell adhesion to laminin 511/521. Cell adhesion and spreading to laminin 511/521 were significantly reinforced in cells expressing Lu RK573-574AA mutant which could be a consequence of its extended half-life at the cell surface. Other proteins of the spectrin-based cytoskeleton, like the adapter protein ankyrin G, can also modulate adhesion molecules' functions including cell adhesion, migration and membrane distribution. The membrane expression of L1CAM, involved in the migration of neuronal growth cones and the static adhesion between adjacent axons, is regulated by its interaction with ankyrin G. Inhibition of this interaction led to retrograde movements of L1CAM in the cell membrane and stimulated L1CAMmediated neurite outgrowth [33].

To date, the Lu/BCAM laminin 511/521 receptor function was known to be activated by two pathways in pathological RBCs: one involving the phosphorylation of its cytoplasmic domain by PKA [2]; and the other mediated by Lu/BCAM cytoplasmic domain interaction with the spectrin-based cytoskeleton $[15,18]$. Our present study indicates that interaction between Lu/BCAM and spectrin regulates epithelial cell adhesion and spreading to laminin 511/521. This regulation is not related to an increased Lu/BCAM phosphorylation of Lu RK573-574AA mutant. Conversely, the laminin 511/521 binding could induce Lu/BCAM cytoplasmic tail phosphorylation, thus modulating its interaction with spectrin. Further experiments should be done to investigate this question.

\section{Consequences on actin dynamics.}

Cell adhesion to extracellular matrix triggers outside-in signaling pathways leading to actin skeleton reorganization with extension of lamellipodia and filopodia. Here, we showed that Lu/BCAM induced stress fibers formation during the early steps of cell adhesion and spreading to laminin $511 / 521$. These changes were due to the Lu/BCAM-laminin 511/521 interaction as cells expressing the D343R mutant, which is defective for laminin 511/521 binding, were unable to induce stress fibers formation. This rearrangement of the actin skeleton was associated with an activation of the small GTP-binding protein RhoA which is known to regulate actin polymerization and stress fibers formation [27]. Similarly, RhoA activation was only observed in cells expressing wt Lu/BCAM. We can conclude that Lu/BCAM binding to laminin 511/521 drives actin filament formation. 
The involvement of laminin $\alpha 5$ in cell spreading and in polymerization of parallel actin filaments, named filipodia-like microspikes, has been also demonstrated in primary dental epithelial cells in which laminin $\alpha 5$ interacts with $\alpha 6 \beta 4$ integrins. This interaction participates in the activation of phosphatidylinositol 3 kinase-Cdc42/Rac pathways [34]. We show that Cdc42/Rac pathways are not involved in the $\mathrm{Lu} / \mathrm{BCAM}$ induced actin reorganization.

The signaling pathway induced by Lu/BCAM binding to laminin 511/521 and leading to actin reorganization requires the Lu/BCAM- $\alpha$ II-spectrin interaction. Disruption of this interaction reduced both the stress fibers formation and the RhoA activation. We showed that both Lu/BCAM isoforms acted similarly regarding actin reorganization. The ability of the short isoform $\mathrm{Lu}(\mathrm{v} 13)$ to induce stress fibers formation indicated that this was independent of the proline-rich SH3-binding domain and the phosphorylation sites present in the long isoform $40 \mathrm{C}$-terminal amino acids. Our results strongly suggest that the signaling cascade leading to actin reorganization upon Lu/BCAM binding to laminin $511 / 521$ is vehicled by spectrin. All these results provide new insights into a novel signaling pathway regulating the actin cytoskeleton via the Lu/BCAM-spectrin interaction that links the upstream laminin $511 / 521$ binding signal to the downstream RhoA activation.

The role of $\alpha$ II-spectrin in actin organization has been recently demonstrated, as $\alpha$ II-spectrin knocked-down melanoma WM-266 cells exhibited modifications of the actin cytoskeleton such as a loss of stress fibers [32]. $\alpha$ II-Spectrin, via its SH3 domain, has been also implicated in initiating Rac activation in the specialized $\beta 3$ integrin clusters that initiate cell adhesion and spreading [35]. Moreover, the SH3 domain of $\alpha$ II-spectrin was demonstrated to bind proteins involved in the regulation of actin cytoskeleton dynamics such as two members of the Mena-VASP family (EVL, VASP) and Tes [36-39]. VASP participates in actin fiber formation and the $\alpha$ II-spectrin-VASP complexes regulate cortical actin cytoskeleton assembly with implications in cell-cell contact formation. Overexpression of TES resulted in increased cell spreading and decreased cell motility whereas Tes knock-down in HeLa cells resulted in loss of actin stress fibers and reduced RhoA activity [40]. All these data reinforce the idea of a pivotal role of spectrin in actin-dependent processes.

In conclusion, spectrin is involved in regulating $\mathrm{Lu} / \mathrm{BCAM}$ function and expression in nonerythroid cells. Our findings provide new evidence that spectrin plays a novel role as a linker between extracellular signals, triggered by laminin 511/521, and intracellular events modulating actin dynamics.

\section{ACKNOWLEDGEMENTS}

*We are grateful to Julien Picot for helpful advice on Flow cytometry experiments.

\section{Founding}

This investigation was supported in part by the Institut National de la Transfusion Sanguine (INTS), the Institut National de la Santé et de la Recherche Médicale (INSERM) and Université Paris Diderot Paris7. 


\section{REFERENCES}

1 Rahuel, C., Le Van Kim, C., Mattei, M. G., Cartron, J. P. and Colin, Y. (1996) A unique gene encodes spliceoforms of the B-cell adhesion molecule cell surface glycoprotein of epithelial cancer and of the Lutheran blood group glycoprotein. Blood. 88, 1865-1872.

2 Gauthier, E., Rahuel, C., Wautier, M. P., El Nemer, W., Gane, P., Wautier, J. L., Cartron, J. P., Colin, Y. and Le Van Kim, C. (2005) Protein kinase A-dependent phosphorylation of Lutheran/basal cell adhesion molecule glycoprotein regulates cell adhesion to laminin alpha5. J. Biol. Chem. 280, 30055-30062

3 Aumailley, M., Bruckner-Tuderman, L., Carter, W. G., Deutzmann, R., Edgar, D., Ekblom, P., Engel, J., Engvall, E., Hohenester, E., Jones, J. C., Kleinman, H. K., Marinkovich, M. P., Martin, G. R., Mayer, U., Meneguzzi, G., Miner, J. H., Miyazaki, K., Patarroyo, M., Paulsson, M., Quaranta, V., Sanes, J. R., Sasaki, T., Sekiguchi, K., Sorokin, L. M., Talts, J. F., Tryggvason, K., Uitto, J., Virtanen, I., von der Mark, K., Wewer, U. M., Yamada, Y. and Yurchenco, P. D. (2005) A simplified laminin nomenclature. Matrix. Biol. 24, 326-332

4 El Nemer, W., Gane, P., Colin, Y., Bony, V., Rahuel, C., Galacteros, F., Cartron, J. P. and Le Van Kim, C. (1998) The Lutheran blood group glycoproteins, the erythroid receptors for laminin, are adhesion molecules. J. Biol. Chem. 273, 16686-16693

5 Udani, M., Zen, Q., Cottman, M., Leonard, N., Jefferson, S., Daymont, C., Truskey, G. and Telen, M. J. (1998) Basal cell adhesion molecule/lutheran protein. The receptor critical for sickle cell adhesion to laminin. J. Clin. Invest. 101, 2550-2558

6 Zen, Q., Cottman, M., Truskey, G., Fraser, R. and Telen, M. J. (1999) Critical factors in basal cell adhesion molecule/lutheran-mediated adhesion to laminin. J. Biol. Chem. 274, 728-734

7 Drewniok, C., Wienrich, B. G., Schon, M., Ulrich, J., Zen, Q., Telen, M. J., Hartig, R. J., Wieland, I., Gollnick, H. and Schon, M. P. (2004) Molecular interactions of B-CAM (basal-cell adhesion molecule) and laminin in epithelial skin cancer. Arch. Dermatol. Res. 296, 59-66

8 Kikkawa, Y. and Miner, J. H. (2005) Review: Lutheran/B-CAM: a laminin receptor on red blood cells and in various tissues. Connect. Tissue. Res. 46, 193-199

9 Vainionpaa, N., Kikkawa, Y., Lounatmaa, K., Miner, J. H., Rousselle, P. and Virtanen, I. (2006) Laminin-10 and Lutheran blood group glycoproteins in adhesion of human endothelial cells. Am. J. Physiol. Cell. Physiol. 290, C764-775

10 Rahuel, C., Filipe, A., Ritie, L., El Nemer, W., Patey-Mariaud, N., Eladari, D., Cartron, J. P., Simon-Assmann, P., Le Van Kim, C. and Colin, Y. (2008) Genetic inactivation of the laminin alpha5 chain receptor $\mathrm{Lu} / \mathrm{BCAM}$ leads to kidney and intestinal abnormalities in the mouse. Am. J. Physiol. Renal. Physiol. 294, F393-406

11 Gane, P., Le Van Kim, C., Bony, V., El Nemer, W., Mouro, I., Nicolas, V., Colin, Y. and Cartron, J. P. (2001) Flow cytometric analysis of the association between blood group-related proteins and the detergent-insoluble material of K562 cells and erythroid precursors. Br. J. Haematol. 113, 680688

12 Kroviarski, Y., El Nemer, W., Gane, P., Rahuel, C., Gauthier, E., Lecomte, M. C., Cartron, J. P., Colin, Y. and Le Van Kim, C. (2004) Direct interaction between the Lu/B-CAM adhesion glycoproteins and erythroid spectrin. Br. J. Haematol. 126, 255-264

13 Parsons, S. F., Lee, G., Spring, F. A., Willig, T. N., Peters, L. L., Gimm, J. A., Tanner, M. J., Mohandas, N., Anstee, D. J. and Chasis, J. A. (2001) Lutheran blood group glycoprotein and its newly characterized mouse homologue specifically bind alpha5 chain-containing human laminin with high affinity. Blood 97, 312-320

14 Bennett, V. and Baines, A. J. (2001) Spectrin and ankyrin-based pathways: metazoan inventions for integrating cells into tissues. Physiol. Rev. 81, 1353-1392 
15 An, X., Gauthier, E., Zhang, X., Guo, X., Anstee, D. J., Mohandas, N. and Chasis, J. A. (2008) Adhesive activity of $\mathrm{Lu}$ glycoproteins is regulated by interaction with spectrin. Blood, blood-20082003-146068

16 Hines, P. C., Zen, Q., Burney, S. N., Shea, D. A., Ataga, K. I., Orringer, E. P., Telen, M. J. and Parise, L. V. (2003) Novel epinephrine and cyclic AMP-mediated activation of BCAM/Lu-dependent sickle (SS) RBC adhesion. Blood. 101, 3281-3287

17 Wautier, M. P., El Nemer, W., Gane, P., Rain, J. D., Cartron, J. P., Colin, Y., Le Van Kim, C. and Wautier, J. L. (2007) Increased adhesion to endothelial cells of erythrocytes from patients with polycythemia vera is mediated by laminin alpha5 chain and Lu/BCAM. Blood. 110, 894-901

18 Gauthier, E., Nemer, W. E., Wautier, M. P., Renaud, O., Tchernia, G., Delaunay, J., Kim, C. L. V. and Colin, Y. (2009) Role of the interaction between Lu/BCAM and the spectrin-based membrane skeleton in the increased adhesion of hereditary spherocytosis red cells to laminin. British. Journal. of. Haematology. 9999

19 Nicolas, G., Fournier, C. M., Galand, C., Malbert-Colas, L., Bournier, O., Kroviarski, Y., Bourgeois, M., Camonis, J. H., Dhermy, D., Grandchamp, B. and Lecomte, M. C. (2002) Tyrosine phosphorylation regulates alpha II spectrin cleavage by calpain. Mol. Cell. Biol. 22, 3527-3536

20 El Nemer, W., Rahuel, C., Colin, Y., Gane, P., Cartron, J. P. and Le Van Kim, C. (1997) Organization of the human LU gene and molecular basis of the $\mathrm{Lu}(\mathrm{a}) / \mathrm{Lu}(\mathrm{b})$ blood group polymorphism. Blood. 89, 4608-4616.

21 Mankelow, T. J., Burton, N., Stefansdottir, F. O., Spring, F. A., Parsons, S. F., Pedersen, J. S., Oliveira, C. L., Lammie, D., Wess, T., Mohandas, N., Chasis, J. A., Brady, R. L. and Anstee, D. J. (2007) The Laminin 511/521-binding site on the Lutheran blood group glycoprotein is located at the flexible junction of Ig domains 2 and 3. Blood. 110, 3398-3406

22 Collec, E., El Nemer, W., Gauthier, E., Gane, P., Lecomte, M. C., Dhermy, D., Cartron, J. P., Colin, Y., Le van Kim, C. and Rahuel, C. (2007) Ubc9 interacts with Lu/BCAM adhesion glycoproteins and regulates their stability at the membrane of polarized MDCK cells. Biochem. J. 402, 311-319

23 Laemmli, U. K. (1970) Cleavage of structural proteins during the assembly of the head of bacteriophage T4. Nature. 227, 680-685

24 El Nemer, W., Colin, Y., Bauvy, C., Codogno, P., Fraser, R. H., Cartron, J. P. and Le Van Kim, C. L. (1999) Isoforms of the Lutheran/basal cell adhesion molecule glycoprotein are differentially delivered in polarized epithelial cells. Mapping of the basolateral sorting signal to a cytoplasmic dileucine motif. J. Biol. Chem. 274, 31903-31908

25 Hall, A. (1994) Small GTP-binding proteins and the regulation of the actin cytoskeleton. Annu. Rev. Cell. Biol. 10, 31-54

26 Ridley, A. J., Paterson, H. F., Johnston, C. L., Diekmann, D. and Hall, A. (1992) The small GTPbinding protein rac regulates growth factor-induced membrane ruffling. Cell. 70, 401-410

27 Tapon, N. and Hall, A. (1997) Rho, Rac and Cdc42 GTPases regulate the organization of the actin cytoskeleton. Curr. Opin. Cell. Biol. 9, 86-92

28 Yonemura, S., Hirao, M., Doi, Y., Takahashi, N., Kondo, T. and Tsukita, S. (1998) Ezrin/radixin/moesin (ERM) proteins bind to a positively charged amino acid cluster in the juxtamembrane cytoplasmic domain of CD44, CD43, and ICAM-2. J. Cell. Biol. 140, 885-895

29 Bolcato-Bellemin, A. L., Lefebvre, O., Arnold, C., Sorokin, L., Miner, J. H., Kedinger, M. and Simon-Assmann, P. (2003) Laminin alpha5 chain is required for intestinal smooth muscle development. Dev. Biol. 260, 376-390

30 Moulson, C. L., Li, C. and Miner, J. H. (2001) Localization of Lutheran, a novel laminin receptor, in normal, knockout, and transgenic mice suggests an interaction with laminin alpha5 in vivo. Dev. Dyn. 222, 101-114. 
31 Nakano, M., Nogami, S., Sato, S., Terano, A. and Shirataki, H. (2001) Interaction of syntaxin with alpha-fodrin, a major component of the submembranous cytoskeleton. Biochem. Biophys. Res. Commun. 288, 468-475

32 Metral, S., Machnicka, B., Bigot, S., Colin, Y., Dhermy, D. and Lecomte, M. C. (2009) AlphaIIspectrin is critical for cell adhesion and cell cycle. J. Biol. Chem. 284, 2409-2418

33 Gil, O. D., Sakurai, T., Bradley, A. E., Fink, M. Y., Cassella, M. R., Kuo, J. A. and Felsenfeld, D. P. (2003) Ankyrin binding mediates L1CAM interactions with static components of the cytoskeleton and inhibits retrograde movement of L1CAM on the cell surface. J. Cell. Biol. 162, 719-730

34 Fukumoto, S., Miner, J. H., Ida, H., Fukumoto, E., Yuasa, K., Miyazaki, H., Hoffman, M. P. and Yamada, Y. (2006) Laminin alpha5 is required for dental epithelium growth and polarity and the development of tooth bud and shape. J. Biol. Chem. 281, 5008-5016

35 Bialkowska, K., Saido, T. C. and Fox, J. E. (2005) SH3 domain of spectrin participates in the activation of Rac in specialized calpain-induced integrin signaling complexes. J Cell Sci. 118, 381-395

36 Bournier, O., Kroviarski, Y., Rotter, B., Nicolas, G., Lecomte, M. C. and Dhermy, D. (2006) Spectrin interacts with EVL (Enabled/vasodilator-stimulated phosphoprotein-like protein), a protein involved in actin polymerization. Biol. Cell. 98, 279-293

37 Rotter, B., Bournier, O., Nicolas, G., Dhermy, D. and Lecomte, M. C. (2005) AlphaII-spectrin interacts with Tes and EVL, two actin-binding proteins located at cell contacts. Biochem. J. 388, 631638

38 Benz, P. M., Blume, C., Moebius, J., Oschatz, C., Schuh, K., Sickmann, A., Walter, U., Feller, S. M. and Renne, T. (2008) Cytoskeleton assembly at endothelial cell-cell contacts is regulated by alphaII-spectrin-VASP complexes. J. Cell. Biol. 180, 205-219

39 Benz, P. M., Blume, C., Seifert, S., Wilhelm, S., Waschke, J., Schuh, K., Gertler, F., Munzel, T. and Renne, T. (2009) Differential VASP phosphorylation controls remodeling of the actin cytoskeleton. J. Cell. Sci. 122, 3954-3965

40 Griffith, E., Coutts, A. S. and Black, D. M. (2005) RNAi knockdown of the focal adhesion protein TES reveals its role in actin stress fibre organisation. Cell. Motil. Cytoskeleton. 60, 140-152 


\section{FIGURE LEGENDS}

Fig.1. (A) Co-immunoprecipitation of $\alpha$ II-spectrin with Lu/BCAM in A498 and MDCK epithelial cells. Lysates from A498 cells expressing both endogenous spectrin and Lu/BCAM, and MDCK cells expressing recombinant wt-Lu or mt-Lu proteins were treated with either the mouse monoclonal anti-Lu/BCAM antibody F241 (Lu), or mouse irrelevant antibody (IgG1) or Protein A Sepharose (PA). Presence of spectrin $(270 \mathrm{kDa})$ and Lu/BCAM $(90 \mathrm{kDa})$ in eluates was detected by Western blot (WB) using a PoAb against the $\alpha$ II-spectrin SH3 domain and a biotinylated goat antiLu/BCAM antibody, respectively. (B) Binding assay of $\alpha$ II-spectrin peptides to Lu/BCAM. $\left[{ }^{35} \mathrm{~S}\right]-$ labeled $\alpha \mathrm{II}$-spectrin peptides corresponding to $\alpha 3 \mathrm{R}, \alpha 4 \mathrm{R}, \alpha 5 \mathrm{R}$ and $\alpha 3->5 \mathrm{R}$ spectrin repeats (TNT products) were incubated with GST, GST-wt-Lu and GST-mt-Lu immobilized on Sepharose 4B glutathione beads. After extensive washing the bound proteins were eluted in Laemmli sample buffer, submitted to electrophoresis and visualized by autoradiography. Spectrin repeats monomers $(*)$ and dimers (**). (C) Triton extractability of Lu/BCAM protein in MDCK cells. MDCK cells expressing either recombinant wt-Lu or $\mathrm{mt}-\mathrm{Lu}$ protein were lysed in the presence of increasing concentrations of Triton X-100. Extracted proteins were analyzed by Western blot using anti$\mathrm{Lu} / \mathrm{BCAM}$ and anti-Ubc9 antibodies. The $20 \mathrm{kDa}$ endogenous cytoplasmic enzyme Ubc9 was used as extraction control.

Fig.2. The expression level and the turnover of Lu/BCAM protein at the membrane of polarized MDCK cells. MDCK cells expressing wt-Lu or mt-Lu were grown on transwell filters. (A) Newlydelivered wt-Lu and $\mathrm{mt}-\mathrm{Lu}$ proteins at the cell surface as determined by autoradiography of biotinylated Lu/BCAM. (B) Western blot showing total amount of wt-Lu or mt-Lu expressed at the membrane at each chase time, (C) The curves show the ratio of "radiolabeled biotinylated Lu/total biotinylated Lu" at the membrane, reflecting the turn-over of newly-delivered wt-Lu $(\boldsymbol{\Delta})$ or $\mathrm{mt}-\mathrm{Lu}(\boldsymbol{\square})$ proteins at the cell surface as a function of time. The curves represent means of 3 experiments.

Fig.3. Adhesion of MDCK cells to laminin 511/521. Mock, wt-Lu or mt-Lu MDCK cells were incubated at $37^{\circ} \mathrm{C}$ for 30,60 and $90 \mathrm{~min}$ in wells coated with either $2 \mu \mathrm{g} / \mathrm{cm}^{2}$ of laminin $511 / 521$ or $1 \%$ BSA. (A) Photos showing cell morphology of each cell line at 90 min. (B) The histogram indicates the percentage of spread cells after 30,60 and 90 min of adhesion to laminin 511/521 or to BSA. (C) The histogram indicates the percentage of adherent cells after $90 \mathrm{~min}$ on laminin 511/521. Each result represents the mean for 8 experiments in duplicates. Statistical significance was determined using Mann-Whitney test $(\mathrm{p}<0.05)$

Fig.4. Phosphorylation of Lu/BCAM protein in MDCK cells. (A) MDCK-wt-Lu and -mt-Lu cells were incubated for $90 \mathrm{~min}$ at $37^{\circ} \mathrm{C}$ with orthophosphate ${ }^{32} \mathrm{P}$ in the absence or presence of PIC (lanes 2 and 5) or br-cAMP (lanes 3 and 6). After immunoprecipitation, radiolabeled Lu/BCAM was analyzed by autoradiography. Western blot (WB) analysis of immunoprecipitated products was performed using Goat biotinylated anti-Lu/BCAM antibody. The $\mathrm{P} / \mathrm{WB}$ ratio represents the proportion of phosphorylated $\mathrm{Lu} / \mathrm{BCAM}$ in total immunoprecipitated Lu/BCAM proteins.

Fig.5. Immunofluorescence studies of actin in adherent MDCK cells. $10^{5}$ mock MDCK cells (a,f), MDCK-wt-Lu (b,g), -D343R-Lu (c,h), -mt-Lu (d,i) or Lu(v13) (e,j) cells were plated for 90 min into wells coated with $2 \mu \mathrm{g} / \mathrm{cm}^{2}$ of laminin 511/521 (left column) or fibronectin (right column). Imaging shows F-actin labeled with phalloidin. Bars $=10 \mu \mathrm{M}$. 
Fig.6. RhoA and Rac 1, 2, 3 and Cdc42 activity assays. The active forms of RhoA, Rac, and Cdc42 were colorimetrically detected using G-LISA kit. (A) RhoA activity (B) Rac1, 2, 3 activities and (C) Cdc42 in MDCK cells plated for $90 \mathrm{~min}$ on either laminin 511/521 or fibronectin. Each result represents the mean of 3 assays performed in duplicates. Statistical significance was determined using Mann-Whitney test $(\mathrm{p}<0.05)$.

Fig.7. Effects of Exoenzyme C3 Transferase on the RhoA-dependent signaling pathway via the Lu/BCAM-spectrin interaction induced stress fibers formation

$10^{5}$ MDCK-wt-Lu, -Lu (v13) and -mt-Lu cells were plated for $90 \mathrm{~min}$ into wells coated with $2 \mu \mathrm{g} / \mathrm{cm}^{2}$ of laminin 511/521 and were untreated (left column) or treated with $1.0 \mu \mathrm{g} / \mathrm{ml}$ of C3 toxin (right column). Imaging shows F-actin labeled with phalloidin. Bars $=10 \mu \mathrm{M}$. 


\section{Fig.1}

A

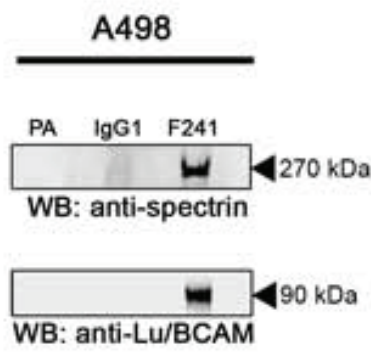

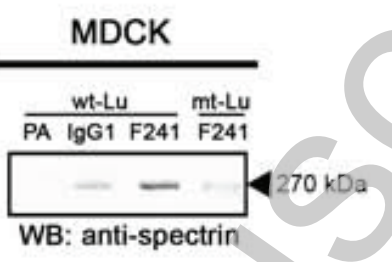

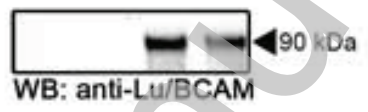

B
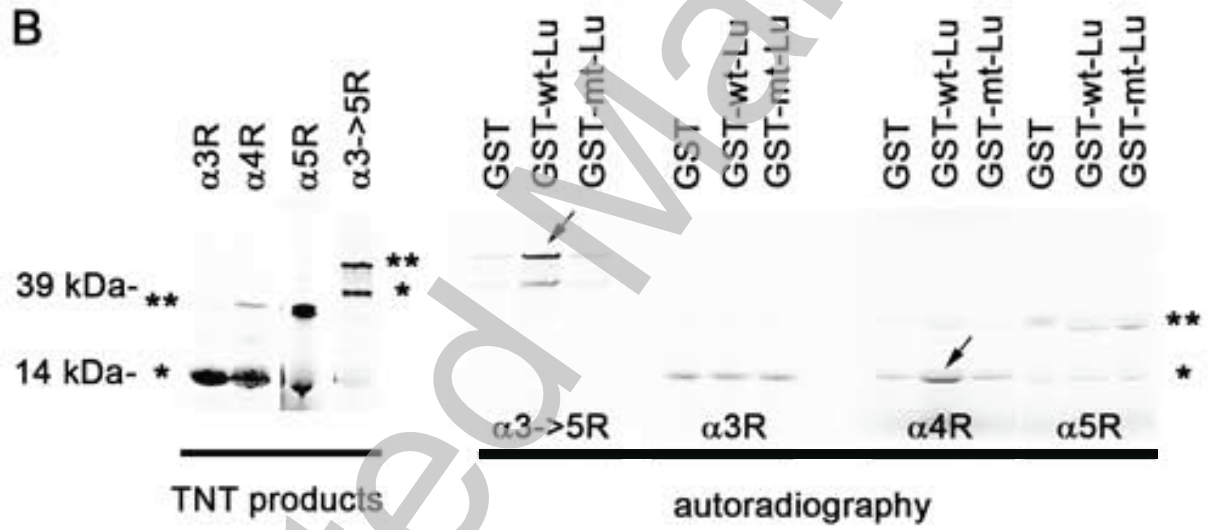

C

wt-Lu

mt-Lu

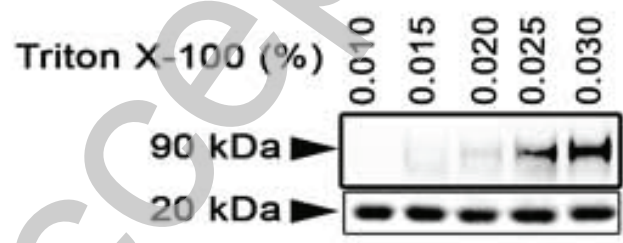

응 눙 옹 ్ㅜㅇ 융

0 O 0 i 0

thtathat Lu/BCAM

$-\infty-\infty<$ Ubc9 
Fig. 2

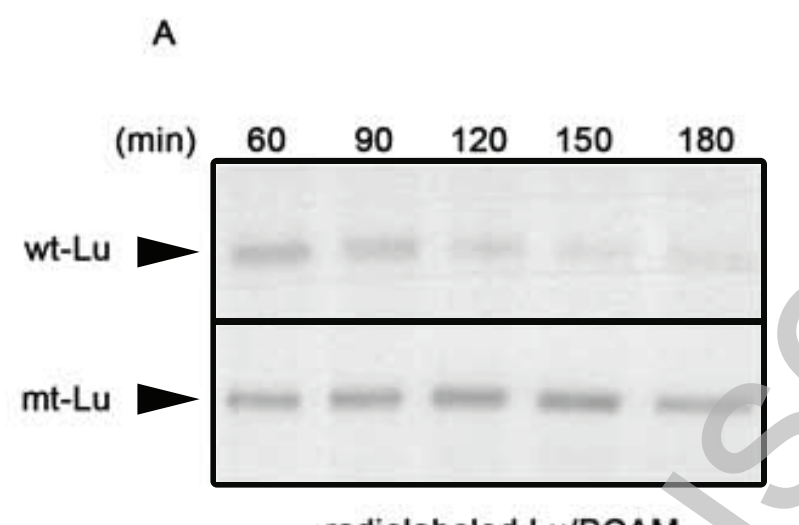

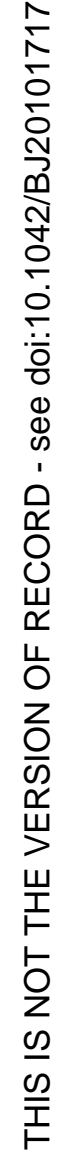

radiolabeled Lu/BCAM

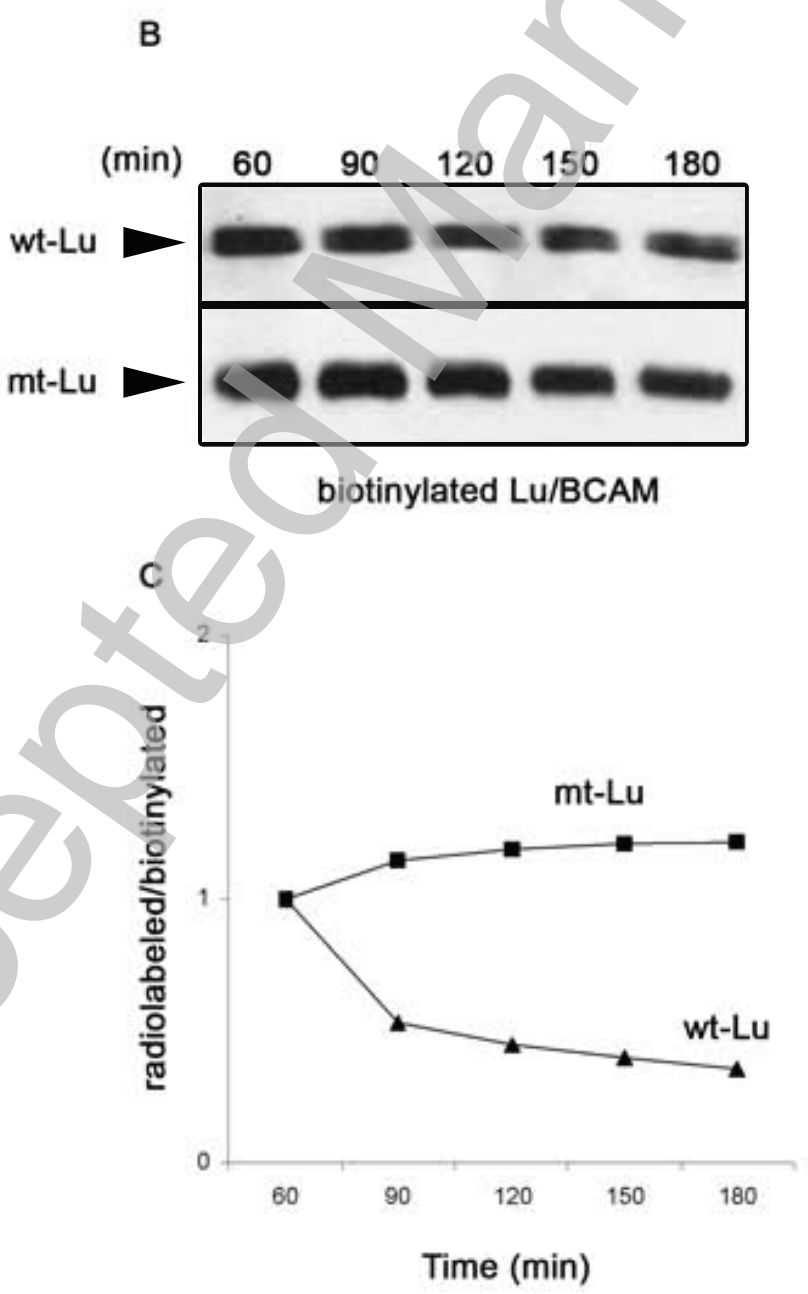

20

Licenced copy. Copying is not permitted, except with prior permission and as allowed by law. (C) 2011 The Authors Journal compilation (c) 2011 Portland Press Limited 
Fig.3

A
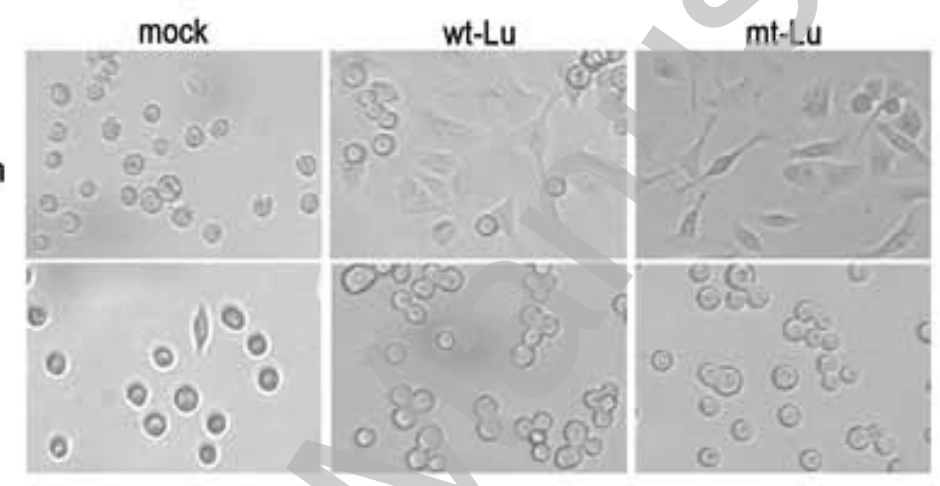

B
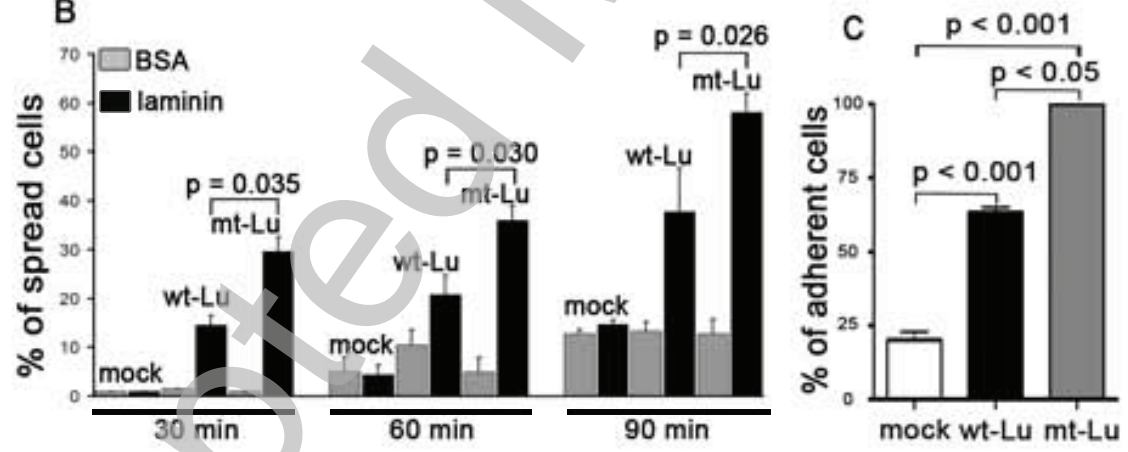


\section{Fig.4}

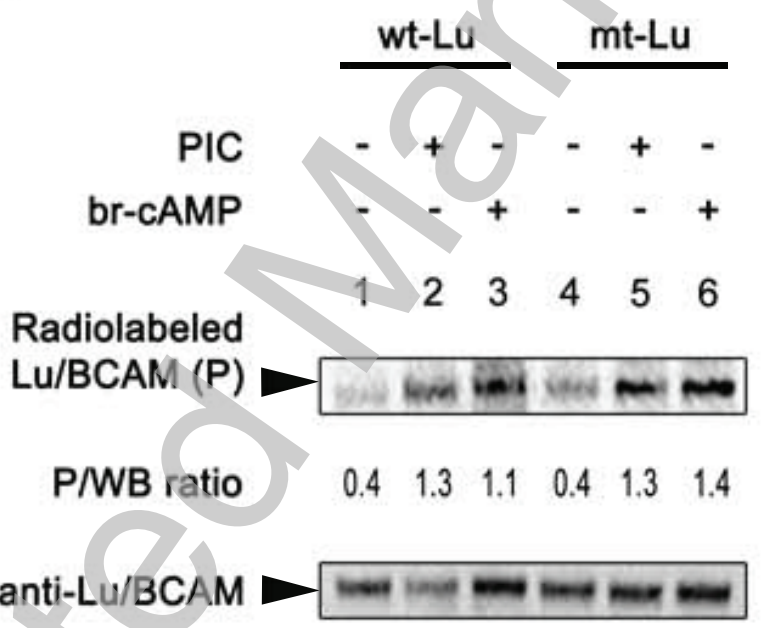


B Biochemical Journal Immediate Publication. Published on 25 Mar 2011 as manuscript BJ20101717

\section{Fig.5}

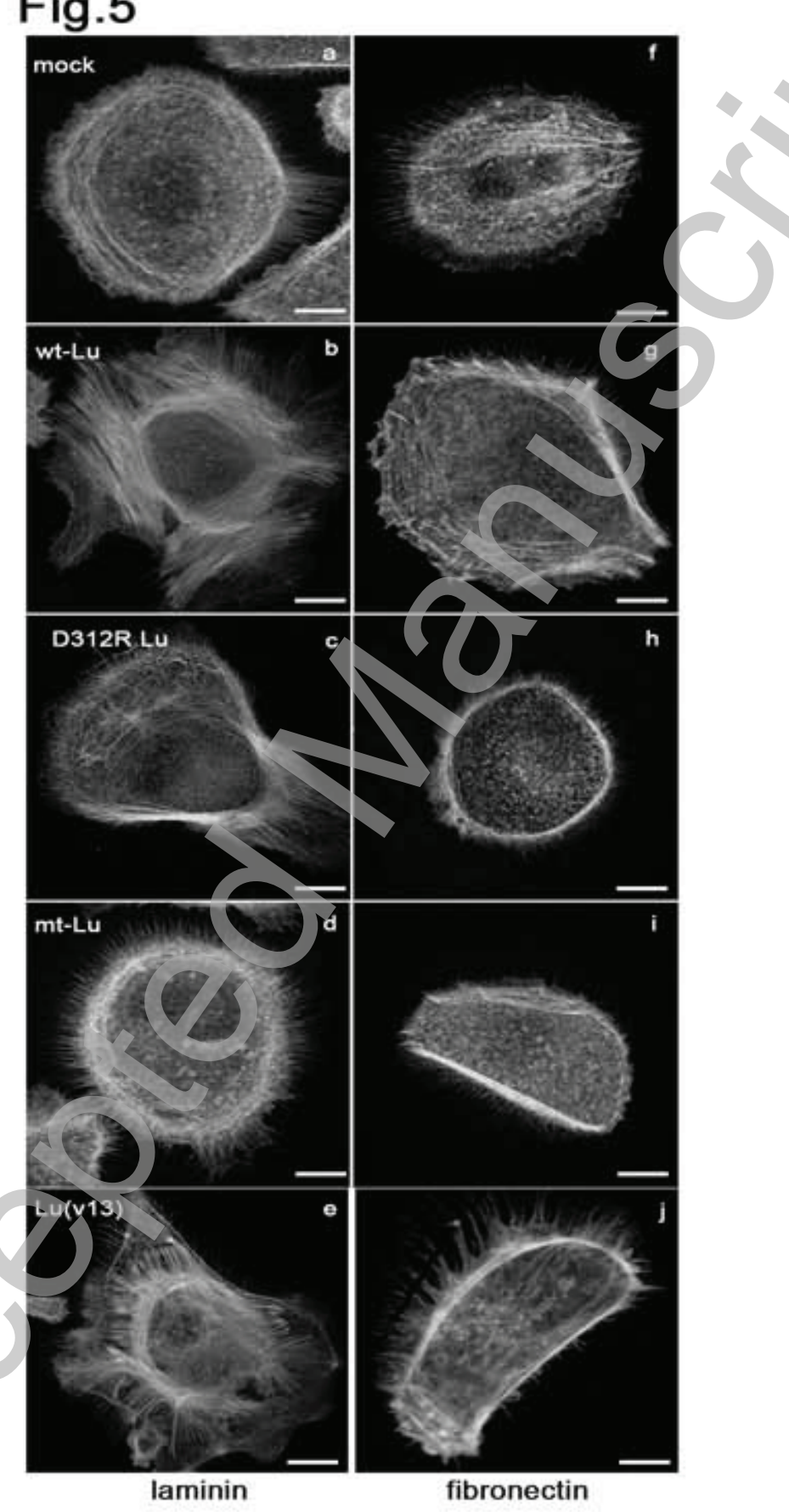


Fig.6

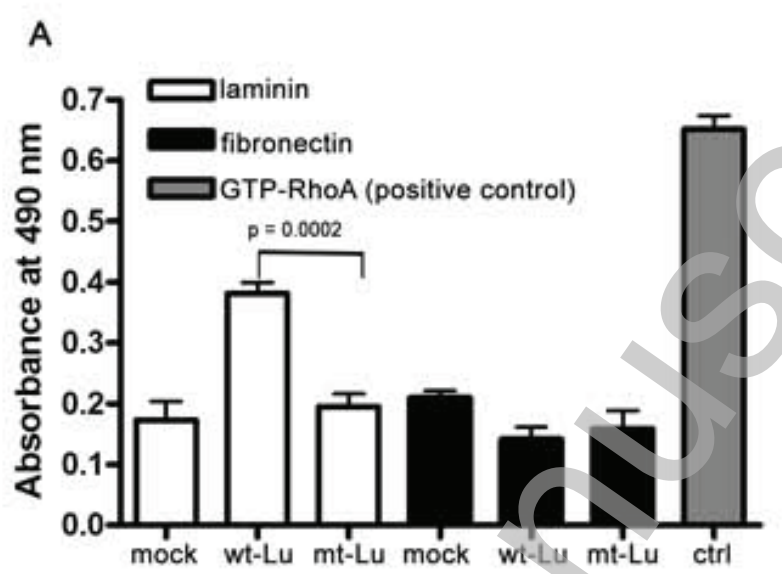

B

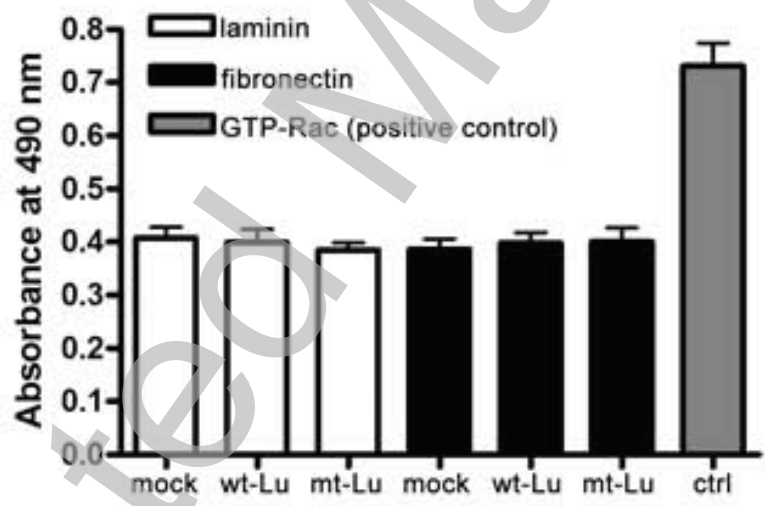

C

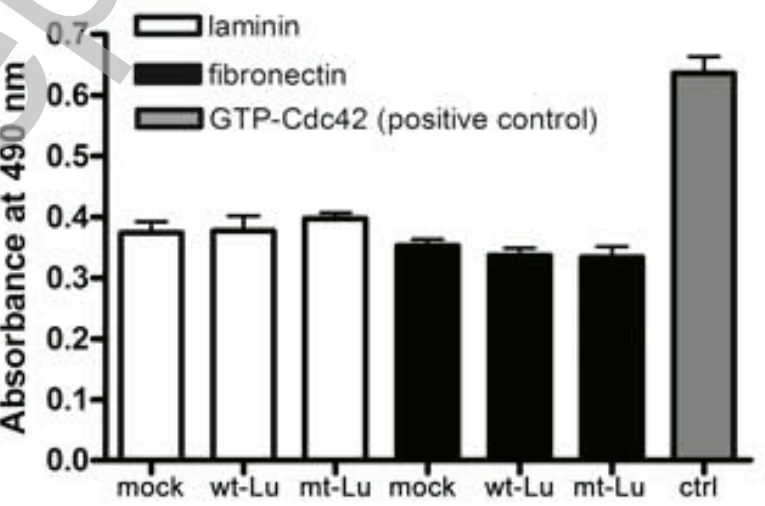


Biochemical Journal Immediate Publication. Published on 25 Mar 2011 as manuscript BJ20101717

\section{Fig.7}

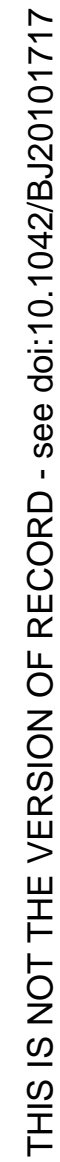

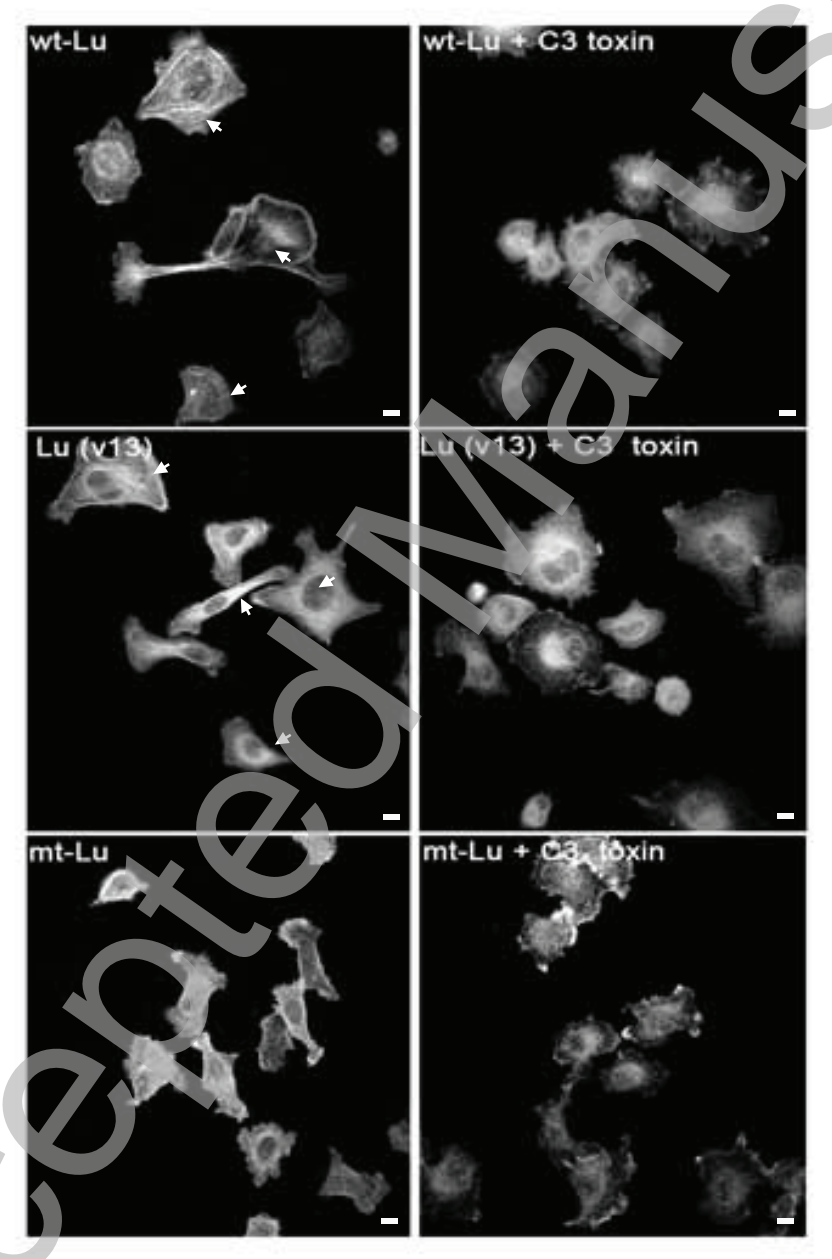

